\title{
PENGARUH KEADILAN ORGANISASIONAL TERHADAP KOMITMEN ORGANISASIONAL YANG DIMEDIASI KEPUASAN KERJA KARYAWAN DI CHILDFUND TIMOR LESTE
}

\author{
Jesuina Soares Cabral ${ }^{1}$ \\ Ni Wayan Sri Suprapti \\ ${ }^{1,2}$ Fakultas Ekonomi dan Bisnis Universitas Udayana (Unud), Bali, Indonesia \\ e-mail: rogeniafour@yahoo.com
}

\begin{abstract}
ABSTRAK
Komitmen organisasional karyawan merupakan hal yang sangat penting bagi suatu organisasi dalam mencapai tujuan-tujuan yang telah ditetapkan. Penelitian ini bertujuan untuk 1) menganalisis pengaruh keadilan organisasional terhadap kepuasan kerja karyawan. 2) menganalisi kepuasan kerja terhadap komitmen komitmen organisasional karyawan.. 3) menganalisis pengaruh keadilan organisasional terhadap kepuasan kerja karyawan. Sampel penelitian adalah seluruh karyawan ChildFund Timor Leste. sebanyak 62 orang. Teknik analisis data mengunakan analisis jalur. Hasil penelitian membuktikan 1) Keadilan organisasional berpengaruhi positif dan signifikan terhadap kepuasan kerja. 2) Kepuasan kerja berpengaruhi positif dan signifikan terhadap komitmen organisasional.. 3) Komitmen berpengaruhi positif dan signifikan terhadap karyawan. Saran yang dapat dikemukakan, ChildFund Timor Leste hendaknya meyakinkan karyawan bahwa kebijakan imbalan yang diterapkan semata-mata untuk menghargai kompetensi karyawan. Selain itu, organisasi diharapkan secara konsisten menerapkan mekanisme keadilan yang secara merata dirasakan oleh semua karyawan baik dari posisi yang rendah hingga posisi yang tertinggi.
\end{abstract}

Kata Kunci : Keadilan Organisasional, Komitmen Oraganisasional, yang dimediasi Kepuasan Kerja Karyawan

\begin{abstract}
Organizational commitment of employees is very important for an organization to achieve the goals that have been set. This study aims to 1) analyze the effect of organizational justice on employee job satisfaction. 2) To analyze job satisfaction on organizational commitment employee commitment. 3) To analyze the effect of organizational justice on employee job satisfaction. The population in this study is total employees working in organizational ChildFund Timor Leste. Based on existing data and the number of employees of the total amount is as much as 58 people. Consisting of employees of International and local employees. To answer the problem of research and test research hypotheses, used path analysis techniques. Managerial implications of this research are ChildFund East Timor can do more in-depth study, if conducted related changes in exchange. In addition, the organization must maintain aspects of procedural justice and interactional as both play a role in shaping employee satisfaction. The advice given is ChildFund East Timor should convince the employee that remuneration policies are applied solely to respect the competence of employees. In addition, organizations are expected to consistently apply justice mechanism that evenly felt by all employees both from a low position up to the highest position. Commitment organizations to pay attention to the satisfaction of all members of the field work.
\end{abstract}

Keywords: Organizational Justice, Commitment Organizational AND Employee Satisfaction. 


\section{PENDAHULUAN}

Orangisasi Non Govermental seperti para LSM di Timor Leste yang sekarang ini mengalami banyak tantangan, karena banyak Negara yang membuka program humanitarian dengan tujuan untuk membantu perkembangan masyarakat Timor Leste yang masih mudah membanggun kemerdekaanya. Tantangan yang dihadapi oleh ChildFund Timor Leste, diantaranya kesulitan untuk mempertahankan karyawan yang baik dalam mencapai tujuan perusahaan. Manusia dianggap asset yang paling penting didalam suatu organisasi. Untuk mendapatkan perhatian yang baik dari seorang pemimpin terhadap karyawan,diperlukan perhatian dari senior manajemen tim untuk memperhatikan keadilan dalam organisasional terhadap karyawannya yang terlihat dari aktivitasaktivitas dalam melaksanakan tugas dan pekerjaannya yang telah diterapkan perusahaan yang dapat memberikan kepuasan kepada karyawan.

Untuk mengunakan manfaat keadilan dalam organisasional semua karyawan melayani sama dalam mata hukum dan procedure organisasi, tidak adanya diskriminasi dan tidak adanya sistem kelurga. Sering kali juga terjadi keadilan yang tidak merata dari kedudukan tinggi sampai ke posisi rendah. Tujuan keadilan fokus kepada pembuatan sistem kompensasi yang mengenali baik kontribusi pekerja (semakin tinggi kinerja atau pengalaman atau training maka semakin tinggi pula kompensasi yang diberikan) dan kebutuhan pekerja (memberikan upah minimum, atau asuransi kesehatan).

Keadilan organisasional mengacu pada saat seorang karyawan merasa diperlakukan dengan adil terhadap semua orang tidak adanya discriminasi. Ini 
adalah kondisi mental yang mengikat individu untuk lembaga, keinginan yang kuat untuk tetap menjadi anggota organisasional tertentu, kesiapan seseorang untuk berjuang tingkat tinggi usaha dan kepercayaan yang kuat dan penerimaan, prinsip-prinsip dan tujuan lembaga (Tella et al. 2007). Perbaikan tingkat loyalitas tidak hanya efek perilaku yang konstruktif, namun menurut hasil saat ini, hasil tidak langsung meningkatkan kepuasan pekerja juga.

Ada kekuatan seperti dalam organisasional adalah bersama dengan peningkatan tingkat kinerja dan tingkat penurunan ketidakhadiran,

Tingkatan Keadilan Distributif : Bakhshi et al (2009), Fatt, Khin et al (2010), karena menemukan bahwa keadilan distributif secara signifikan berhubungan dengan kepuasan gaji, promosi, penilaian kinerja, dan komitmen organisasional sementara keadilan prosedural terkait dengan kepuasan dengan pengawasan, self dilaporkan Peringkat penilaian kinerja, Pertama, terletak pada nilai. Pada tingkat nilai, keadilan hanya berlaku sesuai dengan nilai yang dianut. Prinsip pemerataan dikatakan adil karena nilai tersebut dianut.Kedua, keadilan distributif terletak pada perumusan nilai-nilai menjadi peraturan. Meskipun satu prinsip keadilan distributif telah disepakati sehingga ketidakadilan pada tingkat nilai menjadi tidak muncul, belum tentu keadilan distributif telah ditegakkan.Ketiga keadilan distributif terletak pada implementasi peraturan. Untuk menilai distribusi adil atau tidak, dapat dilihat dari tegaknya peraturan yang diterapkan. Bila peraturan yang disepakati tidak dijalankan sama sekali atau dijalankan sebagian, keadilan distribusi tidak tercapai Van den Bos, (1999). 
Keadilan prosedural lebih berfokus perasaan adil yang dirasakan oleh karyawan mengenai pemberian alokasi suara kepada karyawan dalam prosedurprosedur yang ada pada proses pengambilan keputusan (Perdana,2012). Menurut Nowakowski et al, (2005) para karyawan tidak hanya memberikan reaksi terhadap hasil-hasil (outcomes) yang mereka dapatkan, namum juga terhadap proses-proses bagaimana mereka mendapatkan hasil-hasil tersebut merupakan definisi dari keadilan procedural yang merupakan salah satu dimensi dari keadilan organisasional. Keadilan procedural berkaitan dengan proses atau prosedur untuk mendistribusikan penghargaan Budiarto dan Wardani, (2005). Dengan demikian,keadilan procedural berkaitan dengan apakah pihak karyawan percaya bahwa prosedur dalam proses pengambilan dan penyampaian keputusan dan proses segala bentuk penghargaan yang mereka terima selama ini dalam perusahaan adalah adil bagi merek.

Menurut Suhartini dan Ikwanul (2010) keadilan interaksional merupakan nilai keadilan yang dirasakan karyawan karena adanya proses interaksi dengan pihak lain dalam organisasi baik dari pimpinan maupun rekan sekerja, seorang karyawan merasa diperlakukan secara wajar. Sejauh mana para bawahan dalam organisasi diperlakukan dengan kesopanan, bermartabat dan dengan hormat oleh pihak-pihak yang ada didalam organisasi tersebut Cruceru et al (2009). Berdasarkan pendapat diatas keadilan interaksional merupakan suatu keadilan yang dirasakan para karyawan didalam perusahaan tempat mereka bekerja yand dilihat dari aspek bagaimana hubungan mereka dengan atasan mereka atau sesame rekan kerja, apakah mereka diperakukan dengan hormat dan bermartabat. 
Kepuasan kerja adalah masalah penting bagi semua organisasional tidak peduli apakah dalam organisasional publik atau swasta atau bekerja di negaranegara maju atau terbelakang. Salah satu tujuan untuk gelar ini menarik adalah bahwa personil puas dilaporkan sebagai pekerja yang puas adalah indikasi untuk output dan mujarab operasi organisasional (Robbins \& Coulter, 2005: 370). Kesempatan kerja yang lebih baik diciptakan untuk akademisi dan skala gaji mereka direvisi dan mereka diberikan cukup diinginkan paket gaji, untuk menang atas masalah ketidak adilan, dalam hal gaji (Manzoor et al., 2011). Namun, praktek manajemen publik ditandai dengan kendala yang ditentukan serta peluang kasual. Manajer memiliki alat yang terbatas untuk menginspirasi dan mempertahankan karyawan mereka, karena peraturan karyawan membatasi kapasitas untuk mengidentifikasi dan memberikan imbalan kepada karyawan melalui gaji, up-gradasi, atau bonus. Untuk titik bahwa atribut pribadi mempengaruhi motivasi kerja, pembentukan dapat mengubah sifat-sifat ini yang paling efisien melalui perekrutan, pengangkatan, dan upgrade yang diperlukan orang (Moynihan \& Pandey, 2007).

Menurut Thompson (2003) dalam Jimoh, (2008), untuk mengukur kepuasan karyawan diperlukan pengamat yang membuat keputusan penilaian terhadap kecenderungan perilaku orang yang dievaluasi yang berhubungan dengan kontribusi pada tujuan organisasional.

Menurut Tsuiet al.(1997), kinerja karyawan dapat diukur dengan kuantitas, kualitas, efisiensi, standar professional, kemampuan, penilaian, ketepatan, pengetahuan, dan kreativitas. Menurut Eka Idham Lewa \& Subowo (2005), 
indikator dari komitmen karyawan adalah faktor kualitas kerja; kuantitas; pengetahuan; keandalan; dan kenerja.

Banyak hal yang mendorong terciptanya komitmen organisasi, di antaranya kepuasan-kepuasan yang diperoleh di dalam organisasional atau selama mereka bekerja. Kepuasan akan pembayaran yang diberikan perusahaan, kepuasan kondisi kerja secara mental terkait dengan tantangan pekerjaan yang dihadapi, sikap atasan dan pengawasan yang ada, hubungan dengan sesama rekan kerja yang merupakan faktor faktor penentu komitmen organisasi.

Komitmen organisasional adalah sejauh mana seorang pekerja mengakui dengan organisasional dan keinginan untuk melanjutkan. Ini adalah tingkat kemauan pekerja untuk melanjutkan dengan organisasional di masa depan. Hal ini mencerminkan kepercayaan karyawan dalam misi dan sasaran kerja pendirian dan yang kesediaannya untuk mengeluarkan upaya dalam prestasi mereka dengan maksud untuk melanjutkan bekerja di sana (Singh \& Pandey, 2004: 98).

Komitmen organisasional menunjukkan bahwa ada organisasional dan individu, karena organisasional itu sendiri didirikan oleh individu-individu tertentu yang berkualitas dan memiliki komitment terhadap organisasi. Kebijakankebijakan yang diterapkan dalam organisasional memberikan keuntungan kepada karyawan untuk memahami arti komitmen itu sendiri.

Luthans (1995: 130) mengartikan komitmen organisasional sebagai:

a. A strong desire to remain a member of particular orgniszation. Keinginan yang kuat untuk menpertahankan seorang anggota organisasional tertentu. 
b. A willingness to exert high leves of effort on behalf of the organization. Sebuah kemauan yang kuat untuk berusaha mempertahankan nama organisasi. c. A definite in, and acceptmance of, the values and goals of the organization. Keyakinan dan penerimaan nilai-nilai dan tujuan organisasi.

Banyak hal yang mendorong terciptanya komitmen organisasi, di antaranya kepuasan-kepuasan yang diperoleh di dalam organisasional atau selama mereka bekerja. Kepuasan akan pembayaran yang diberikan perusahaan, kepuasan kondisi kerja secara mental terkait dengan tantangan pekerjaan yang dihadapi, sikap atasan dan pengawasan yang ada, hubungan dengan sesama rekan kerja yang merupakan faktor faktor penentu komitmen organisasi. Komitmen organisasional yang tinggi tidak bisa muncul dengan sendirinya. Karena ada banyak faktor yang berperan di dalamnya seperti yang dinyatakan oleh Harrison dan Hubard (Febriani, 2004) yaitu kepuasan kerja, kepercayaan terhadap pemimpin, keikutsertaan karyawan dalam mengambil keputusan, usia, perilaku pimpinan dan masa kerja.

Komitmen organisasional adalah sejauh mana seorang pekerja mengakui dengan organisasional dan keinginan untuk melanjutkan. Ini adalah tingkat kemauan pekerja untuk melanjutkan dengan organisasional di masa depan. Hasil penilaian keadilan organisasional terhadap komitmen organisasional yang dimediasi kepuasan masih berada diposisi tidak terlalu rendah atau buruk di ChildFund Timor Leste. Keadilan organisasional dari analisis data yang telah diedarkan menyatakan dalan hasil bahwa menerima imbalan yang layak dari 58 orang responden baik dengan nilai 3.47 . Hal ini tingkat keadilan sudah berlaku 
adil dalam organisasional ChildFund Timor Leste. persedure pemberian penghargaan dalam organisasional ChildFund Timor Leste dari 58 orang responden menyatakan dengan nilai 3.56 cukup baik. Hal ini menunjukan bahwa tingkat prosedural perluh diperhatikan dan diperbaiki. Untuk keseluruhan keadilan organisasional dari 58 orang responden menyatakan cukup baik. Responden menilai keadilan yang diterapkan dalam organisasional masih relatif kurang belum effectif dan effiesien. Usulan dari peneliti keorganisasional ChildFund Timor Leste agar meningkatkan nilai-nilai keadilan yang dapat memuaskan karyawan di ChildFund Timor Leste. Selain keadilan, faktor yang mempengaruhi komitmen organisasional yaitu kepuasan kerja karyawan berpengaruh signifikan komitmen organisasi. Ini berarti komitmen organisasional memberikan pengaruh positif dan signifikan terhadap kepuasan karyawan. Semakin tinggi keadilan organisasional dari karyawan maka akan semakin meningkat individual karyawan.Sejumlah penelitian menunjukan bahwa status karyawan seseorang dapat mempengaruhi komitmen organisasionalnya seperti pada penelitian Avisina (2010) menyatakan karyawan tetap dan karyawan kontrak memiliki perbedaan mendasar yang menyangkut berbagai aspek, diantaranya mengenai status karyawan, tingkat rasa aman dalam bekerja, orientasi karir, dan lamanya waktu dalam bekerja masa kerja.

Penelitian yang dilakukan oleh Adams (dalam Fischer, 2002:1). Menyatakan keadilan organisasional sebagai akibat ketidakpuasan atas keputusan yang telah dihasilkan oleh pihak manajemen yang dirasakan tidak adil oleh karyawan. Tidak heran jika kemudian bermunculan ketidak puasan karyawan 
akhirnya dia harus meninggalkan organisasi, atau kurang effectif melaksanakan tugas dan tanggung jawab sesuai tuntutan normatif. Bierhoff dalam Pareke (2003) menyatakan bahwa perdebatan mengenai teori keadilan organisasional pada mulanya lebih menekankan pada aspek keadilan distributif, namun pada akhirakhir ini perspektif keadilan prosedural semakin banyak mendapatkan perhatian peneliti.

Penelitian ini didasari oleh penelitian yang dilakukan oleh McFarlin dan Sweeney dalam Harris (2000) yang menyatakan bahwa penelitian mengenai keadilan organisasional menyatakan bahwa keadilan distributif memiliki pengaruh terhadap perasaan keadilan terhadap hasil akhir, yang mempengaruhi kinerja juga, meskipun lebih rendah daripada keadilan prosedural. Penelitian lain menunjukkan bahwa individu akan menampilkan tingkat kinerja dan tingkat komitmen yang lebih tinggi, peningkatan kerja dan kepuasan pembayaran, peningkatan tingkat kepercayaan, dan sikap anggota organisasional ketika mereka merasa bahwa proses pengambilan keputusan adil, dan mereka diperlakukan dengan adil, Rupp dan Cropanzano dalam Byrne et al., (2003). Selain dua penelitian diatas, penelitian lain yang digunakan sebagai dasar adalah penelitian yang dilakukan oleh Pareke (2003) yang menyimpulkan bahwa keadilan distributif dan prosedural memiliki peran penting dalam rangka meningkatkan komitmen organisasi.

Penelitian ini dilakukan pada ChildFund Timor Leste yang bekerja untuk memberikan perlingdungan hak-hak anak sejak tahun 1999 ketika Timor Leste menhadapi masa-masah krisis. Setelah Timor Leste terlepas dari Negara Kesatuan Republik Indonesia sebagai hasil referendum yang dipimpin oleh United Nations 
(UN) pada bulan Agustus 1999, ChildFund mulai beroperasi untuk mendukung pemerintah transisi UN di Timor Leste membangun dan memulihkan kembali kehidupan anak-anak dari masa kehancuran secara luas oleh para militar pendukung anti kemerdekaan Timor Leste.

Kepuasan organisasional dari analisis data yang telah diedarkan menyatakan dalan hasil bahwa karyawan merasa puas terhadap gaji dan tunjangan yang diterima, juga puas terhadap pekerjaan hal ini diketahui dari 58 orang responden baik dengan nilai 3.06. Hal ini tingkat kepuasan sudah berlaku baik dalam organisasional ChildFund Timor Leste.

Kepuasan tentang penyelia dimana karyawan dapat berintegrasi dengan orang lain dalam kondisi kerja di organisasional ChildFund Timor Leste. Dari 58 orang responden menyatakan dengan nilai 3.38 cukup baik. Hal ini menunjukan bahwa tingkat kepuasan lewat cara beinteraksi diantara karyawan cukup baik namun perluh diperhatikan dan ditingkatkan. Responden menilai kepuasan yang diterapkan dalam organisasional masih relatif kurang belum effectif dan effiesien. Usulan dari peneliti keorganisasional ChildFund Timor Leste agar meningkatkan nilai-nilai kepuasan pada karyawan di ChildFund Timor Leste.

Kepuasan terhadap gaji adalah imbalan yang diterima karyawan berkaitan dengan pekerjaan yang dibebankan kepadanya. Kepuasan terhadap kebijakan adalah kejelasan kebijakan organisasional berkaitan dengan promosi dan pengembangan karir karyawan. Kepuasan dalam hubungan dengan rekan kerja adalah hubungan yang terbina antara rekan sekerja dalam menyelasaikan pekerjaan. Kepuasan terhadap pekerjaan itu sendiri adalah jenis dan sifat 
pekerjaan dan tanggung jawab yang dapat diselesikan sesuai dengan kompetensi para pegawai. Kepuasan terhadap lingkungan dan kepuasan kerja adalah kondisi lingkungan tempat kerja dimana pegawai melakukan pekerjaanya setiap hari. Hubungan antara keadilan organisasional dan komitmen signifikan positif terhadap kepuasan karyawan.

Berdasarkan uraian di dalam latar belakang masalah, maka hal-hal yang menjadi pokok masalah di dalam penelitian ini adalah: (1 )Bagaimana pengaruh keadilan organisasional terhadap kepuasan para karyawan di ChildFund Timor Leste? (2)Bagaimana Pengaruh kepuasan kerja terhadap komitmen organisasional di karyawan ChildFund Timor Leste? (3)Bagaimanakah pengaruh keadilan organisasional terhadap komitmen organisasi karyawan di ChildFun Timor Leste?

Untuk menjawab permasalahan tersebut disusun kerangka konseptual pada gambar diatas, Hipotesis disusun berdasarkan latar belakang yang telah diuraikan sebelumnya sehingga dapat dirumuskan sebagai berikut:

H1. Keadilan Organisasional berpengaruhi positif dan signifikan terhadap kepuasan kerja.

H2. Kepuasan kerja berpengaruh positif dan significant terhadap Komitmen Organisasi

H3. Keadilan organisasional berpengaruhi positif dan significant terhadap komitmen organisasional. 


\section{METODE PENELITIAN}

Lokasi penelitian ini adalah organissi ChildFund Timor Leste di Dili. Obyek peneliti adalah karyawan ChildFund Timor Lesre. Populasi dalam penelitian ini adalah karyawan sebanyak 58 orang yang terdiri karyawan internasional dan karyawan lokal.. Variabel pada penelitian ini yaitu variabel keadilan organisasional terhadap komitmen organisasional yang dimediasi kepuasan karyawan di ChildFund Timor Leste.

Variabel yang digunakan dalam penelitian ini dapat dikelompokan menjadi variabel eksogen dan endogen Variabel eksogen dalam penelitian ini adalah Keadilan organisasional (X). Variabel endogen meliputi kepuasan Kerja (Y1), dan Komitmen Organisasional (Y2)

Dalam penelitian ini digunakan instrumen sebagai alat pengumpulan data. Sebelum digunakan terlebih dahulu dilakukan pengujian validitas dan reliabilitas instrumen. Dalam pengujian validitas instrumen digunakan validitas kriteria, yaitu dihitung berdasarkan korelasi antara skor tiap butir dengan skor total indikator. Instrumen dikatakan valid jika memiliki korelasi positif dan lebih besar 0,30. Dari hasil uji validitas instrumen, terbukti bahwa instrumen dapat dinyatakan valid karena seluruh butir pertanyaan dalam instrumen untuk semua variabel memiliki koefisien korerasi di atas 0,30 ( $r>0,30)$.

Dalam pengujian reliabilitas instrumen digunakan reliabilitas konsistensi internal, yaitu dengan menghitung Alpha Cronbach. Instrumen penelitian dikatakan reliabel jika memiliki Alpha Cronbach lebih besar atau sama dengan 0,60 ( $\alpha \geq 0,60)$. Dari hasil pengujian reliabilitas instrumen ternyata instrumen 
dapat dikatakan reliabel karena Alpha Cronbach untuk tiap variabel lebih besar dari 0,60 .

\section{HASIL PENELITIAN DAN PEMBAHASAN}

Dalam deskripsi variabel penelitian ini diuraikan gambaran dari tiap-tiap variabel penelitian berdasarkan hasil penilaian responden terhadap butir-butir pertanyaan dalam instrumen penelitian. Dalam mendeskripsikan masing-masing variabel yaitu keadilan organisasional (X), Kepuasan kerja (Y1) dan Komitmen Organisasional(Y2) didasarkan pada nilai rata-rata skor jawaban responden atas butir-butir pertanyaan dalam instrumen penelitian. Dalam menginterpretasi nilai rata-rata skor tiap variabel digunakan kriteria berikut.

Tabel 1.

Nilai Rata-Rata Skor

\begin{tabular}{cc}
\hline Rentangan nilai rata-rata skor & Interpretasi \\
\hline $1,00-1,80$ & sangat buruk \\
$1,81-2,61$ & Buruk \\
$2,62-3,42$ & cukup baik \\
$3,43-4,23$ & Baik \\
$4,24-5,00$ & sangat baik \\
\hline
\end{tabular}

Pada bagian berikut ini diuraikan secara berturut-turut variabel Keadilan Organisasional (X), Kepuasan kerja (Y1) dan Komitmen Organisasional(Y2).

\section{1). Deskripsi Variabel Keadilan Organisasional (X),}

Hasil analisis deskriptif variabel Keadilan Organisasional (X) berupa proporsi jawaban responden pada alternatif jawaban untuk setiap butir pertanyaan, nilai skor rata-rata setiap butir dan nilai rata-rata skor setiap indikator serta nilai skor rata-rata keseluruhan untuk variabel, disajikan pada tabel berikut: 
Tabel 2.

Deskripsi Variabel Kadilan Organisasional (X)

\begin{tabular}{|c|c|c|c|c|c|c|c|}
\hline \multirow[b]{2}{*}{ Idikator } & \multicolumn{6}{|c|}{ Persentase Jawaban Responden } & \multirow{2}{*}{$\begin{array}{c}\text { Keteran } \\
\text { gan }\end{array}$} \\
\hline & STS & TS & $\mathrm{CS}$ & $S$ & SS & $\begin{array}{l}\text { Rata- } \\
\text { Rata }\end{array}$ & \\
\hline $\begin{array}{l}\text { Menerima imbalan yang layak } \\
\text { sesuai dengan tanggung Jawab } \\
\text { tugas yang dibebankan } \\
\text { organisasionalini }\end{array}$ & 3,45 & $\begin{array}{l}12,0 \\
7\end{array}$ & 29,31 & $\begin{array}{l}37,9 \\
3\end{array}$ & 17,24 & 3,53 & Baik \\
\hline $\begin{array}{l}\text { Imbalan yang diberikan } \\
\text { organisasional ini cukup } \\
\text { memenuhi kebutuhan hidup }\end{array}$ & 3,45 & $\begin{array}{l}20,6 \\
9\end{array}$ & 29,31 & $\begin{array}{l}27,5 \\
9\end{array}$ & 18,97 & 3,38 & $\begin{array}{l}\text { cukup } \\
\text { baik }\end{array}$ \\
\hline $\begin{array}{l}\text { Imbalan bidang tanggung } \\
\text { jawab sesuai dengan harapan }\end{array}$ & 3,45 & $\begin{array}{l}17,2 \\
4\end{array}$ & 29,31 & $\begin{array}{l}27,5 \\
9\end{array}$ & 22,41 & 3,48 & Baik \\
\hline Keadilan Distributif & & & & & & $\mathbf{3 , 4 7}$ & Baik \\
\hline $\begin{array}{l}\text { Prosedur pemberian } \\
\text { penghargaan (imbalan) } \\
\text { diterapkan secara konsisten } \\
\text { untuk semua bidang tanggung } \\
\text { jawab. }\end{array}$ & 1,72 & $\begin{array}{l}17,2 \\
4\end{array}$ & 27,59 & $\begin{array}{l}29,3 \\
1\end{array}$ & 24,14 & 3,57 & Baik \\
\hline $\begin{array}{lr}\text { Procedur } & \text { pemberian } \\
\text { penghargaan } & \text { (imbalan) } \\
\text { diaplikasikan secara konsisten } \\
\text { sepanjang waktu. }\end{array}$ & 1,72 & $\begin{array}{l}15,5 \\
2\end{array}$ & 43,10 & $\begin{array}{l}29,3 \\
1\end{array}$ & 10,34 & 3,31 & $\begin{array}{l}\text { cukup } \\
\text { baik }\end{array}$ \\
\hline $\begin{array}{l}\text { Pembuatan keputusan } \\
\text { berkaitan dengan imbalan } \\
\text { disampaikan dengan jelas oleh } \\
\text { pihak manajemen }\end{array}$ & 5,17 & $\begin{array}{l}18,9 \\
7\end{array}$ & 36,21 & $\begin{array}{l}32,7 \\
6\end{array}$ & 6,90 & 3,17 & $\begin{array}{l}\text { cukup } \\
\text { baik }\end{array}$ \\
\hline Keadilan Prosedural & & & & & & 3,35 & $\begin{array}{l}\text { cukup } \\
\text { baik }\end{array}$ \\
\hline $\begin{array}{l}\text { Diberi informasi tentang apa } \\
\text { yang terjadi berkaitan dengan } \\
\text { pekerjaan }\end{array}$ & 1,72 & 17,24 & 34,48 & $\begin{array}{l}32,7 \\
6\end{array}$ & 13,79 & 3,40 & $\begin{array}{l}\text { cukup } \\
\text { baik }\end{array}$ \\
\hline $\begin{array}{l}\text { Diberi informasi tentang apa } \\
\text { yang terjadi dalam } \\
\text { organisasional ChildFund. }\end{array}$ & 0,00 & 20,69 & 36,21 & 29,31 & 13,79 & 3,36 & $\begin{array}{l}\text { cukup } \\
\text { baik }\end{array}$ \\
\hline $\begin{array}{l}\text { Informasi yang diterima secara } \\
\text { akurat dan tepat }\end{array}$ & 3,45 & 22,41 & 34,48 & $\begin{array}{l}25,8 \\
6\end{array}$ & 13,79 & 3,24 & $\begin{array}{l}\text { cukup } \\
\text { baik }\end{array}$ \\
\hline $\begin{array}{l}\text { Bebas untuk menyampaikan } \\
\text { pendapat dan apa saja menjadi } \\
\text { perhatian. }\end{array}$ & 0,00 & 24,14 & 39,66 & 27,59 & 8,62 & 3,21 & $\begin{array}{l}\text { cukup } \\
\text { baik }\end{array}$ \\
\hline Keadilan Interaksional & & & & & & 3,30 & $\begin{array}{l}\text { cukup } \\
\text { baik }\end{array}$ \\
\hline Keadilan Organisasional & & & & & & 3,37 & $\begin{array}{l}\text { cukup } \\
\text { baik }\end{array}$ \\
\hline
\end{tabular}

Berdasarkan tabel 2 keadilan organisasional dari analisis data yang telah diedarkan menyatakan dalan hasil bahwa menerima imbalan yang layak dari 58 
orang responden baik dengan nilai 3.47. Hal ini tingkat keadilan sudah berlaku adil dalam organisasional ChildFund Timor Leste. persedure pemberian penghargaan dalam organisasional ChildFund Timor Leste dari 58 orang responden menyatakan dengan nilai 3.56 cukup baik. Hal ini menunjukan bahwa tingkat prosedural perluh diperhatikan dan diperbaiki. Untuk keseluruhan keadilan organisasional dari 58 orang responden menyatakan cukup baik. Responden menilai keadilan yang diterapkan dalam organisasional masih relatif kurang belum effectif dan effiesien. Usulan dari peneliti keorganisasional ChildFund Timor Leste agar meningkatkan nilai-nilai keadilan yang dapat memuaskan karyawan di ChildFund Timor Leste.

2) Deskripsi Variabel Kepuasan Kerja

Variabel kepuasan kerja diukur dengan tiga kategori dengan sepuluh pernyataan penilaian responden terhadap indikator variabel kepuasan kerja ditunjukan pada tabel 3 sebagai berikut;

Tabel 3.

Deskripsi Variabel Kepuasan kerja (Y1)

\begin{tabular}{|c|c|c|c|c|c|c|c|}
\hline \multirow[b]{2}{*}{ Idikator } & \multicolumn{5}{|c|}{ Persentase Jawaban Responden } & \multirow[b]{2}{*}{$\begin{array}{l}\text { Rata- } \\
\text { rata }\end{array}$} & \multirow{2}{*}{$\begin{array}{c}\text { Keter } \\
\text { anga } \\
\text { n }\end{array}$} \\
\hline & STS & TS & CS & $\mathbf{S}$ & SS & & \\
\hline $\begin{array}{l}\text { Merasa puas terhadap gaji yang } \\
\text { diterima dibandingkan } \\
\text { perkerjaan yang dilakukan }\end{array}$ & 8,62 & 24,14 & 37,93 & 25,86 & 3,45 & 2,91 & $\begin{array}{l}\text { cukup } \\
\text { baik }\end{array}$ \\
\hline $\begin{array}{l}\text { Merasa puas dan melaksanakan } \\
\text { pekerjaan dengan baik dapat } \\
\text { dipromosikan }\end{array}$ & 1,72 & 18,97 & 29,31 & 25,86 & 24,14 & 3,52 & Baik \\
\hline $\begin{array}{l}\text { Puas dengan tunjangan } \\
\text { yang diterima cukup } \\
\text { banyak }\end{array}$ & 8,62 & 31,03 & 37,93 & 20,69 & 1,72 & 2,76 & $\begin{array}{l}\text { cuk } \\
\text { up } \\
\text { baik }\end{array}$ \\
\hline Kepuasan Gaji & & & & & & 3,06 & $\begin{array}{l}\text { cukup } \\
\text { baik }\end{array}$ \\
\hline $\begin{array}{l}\text { Puas dengan informasi tentang } \\
\text { keputusan dari atasan terhadap } \\
\text { kemampuan. }\end{array}$ & 0,00 & 8,62 & 39,66 & 43,10 & 8,62 & 3,52 & Baik \\
\hline $\begin{array}{l}\text { Merasa puas terhadap manager } \\
\text { dalam memberikan motivasi? }\end{array}$ & 0,00 & 20,69 & 32,76 & 31,03 & 15,52 & 3,41 & $\begin{array}{l}\text { cukup } \\
\text { baik }\end{array}$ \\
\hline
\end{tabular}




\begin{tabular}{|c|c|c|c|c|c|c|c|}
\hline Merasa puas terhadap pekerjaan & 3,45 & 15,52 & 34,48 & 37,93 & 8,62 & 3,33 & cukup \\
\hline $\begin{array}{l}\text { Menerima umpan balik yang } \\
\text { cukup dari atasans mengenai } \\
\text { seberapa baik saya bekerja. }\end{array}$ & 1,72 & 22,41 & 31,03 & 36,21 & 8,62 & 3,28 & $\begin{array}{l}\text { cukup } \\
\text { baik }\end{array}$ \\
\hline Kepuasan tehadap Penyelia & & & & & & 3,38 & $\begin{array}{l}\text { cukup } \\
\text { baik }\end{array}$ \\
\hline $\begin{array}{l}\text { Saya Puas dengan } \\
\text { keanekaragaman kegiatan } \\
\text { pekerjaan saya }\end{array}$ & 0,00 & 10,34 & 27,59 & 48,28 & 13,79 & 3,66 & Baik \\
\hline $\begin{array}{l}\text { Saya puas dengan kesempatan } \\
\text { yang ada dalam pekerjaan saya } \\
\text { untuk berinteraksi untuk } \\
\text { berinteraksi dengan orang lain. }\end{array}$ & 0,00 & 1,72 & 27,59 & 46,55 & 22,41 & 3,84 & Baik \\
\hline $\begin{array}{l}\text { Saya merasa puas dengan } \\
\text { tingkat pekerjaan saya dalam } \\
\text { kondisi kerja saya }\end{array}$ & 0,00 & 10,34 & 37,93 & 44,83 & 6,90 & 3,48 & Baik \\
\hline Kepuasan terhadap. Pekerjaan & & & & & & 3,66 & Baik \\
\hline Kepuasan Kerja (Y1) & & & & & & 3,37 & $\begin{array}{l}\text { cukup } \\
\text { baik }\end{array}$ \\
\hline
\end{tabular}

Berdasarkan pada tabel 3 Kepuasan organisasional dari analisis data yang telah diedarkan menyatakan dalan hasil bahwa karyawan merasa puas terhadap gaji dan tunjangan yang diterima, juga puas terhadap pekerjaan hal ini diketahui dari 58 orang responden baik dengan nilai 3.06. Hal ini tingkat kepuasan sudah berlaku baik dalam organisasional ChildFund Timor Leste.

Kepuasan tentang penyelia dimana karyawan dapat berintegrasi dengan orang lain dalam kondisi kerja di organisasional ChildFund Timor Leste. Dari 58 orang responden menyatakan dengan nilai 3.38 cukup baik. Hal ini menunjukan bahwa tingkat kepuasan lewat cara beinteraksi diantara karyawan cukup baik namun perluh diperhatikan dan ditingkatkan. Responden menilai kepuasan yang diterapkan dalam organisasional masih relatif kurang belum effectif dan effiesien. Usulan dari peneliti keorganisasional ChildFund Timor Leste agar meningkatkan nilai-nilai kepuasan pada karyawan di ChildFund Timor Leste.

3) Deskripsi Variabel Komitmen Organisasional 
ISSN : 2337-3067

E-Jurnal Ekonomi dan Bisnis Unud 6.7 (2017) : 2889-2916

Variabel komitmen oranisasi ini diukur dengan tiga indikator dengan 10 pernyataan. Penilaian responden terhadap indikator variabel komitmen organisasional ditunjukan pada tabel 4 sebagai berikut.

Tabel 4.

Komitmen Organisasional (Y2)

\begin{tabular}{|c|c|c|c|c|c|c|c|}
\hline \multirow{2}{*}{ Idikator } & \multicolumn{6}{|c|}{ Persentase Jawaban Responden } & \multirow{2}{*}{$\begin{array}{l}\text { Keteran } \\
\text { gan }\end{array}$} \\
\hline & STS & $\mathrm{TS}$ & $\mathrm{CS}$ & $\mathrm{S}$ & $\mathrm{SS}$ & rata & \\
\hline $\begin{array}{l}\text { Alasan lebih menyukai } \\
\text { organisasionalini dari pada } \\
\text { organisasional yang lain } \\
\text { sebab nilai-nilai } \\
\text { organisasionalini cocok }\end{array}$ & 0,00 & 10,34 & 18,97 & 55,17 & 15,52 & 3,76 & Baik \\
\hline $\begin{array}{l}\text { Merasa senang } \\
\text { menghabiskan waktu karir } \\
\text { dengan organisasionalini }\end{array}$ & 0,00 & 6,90 & 34,48 & 46,55 & 12,07 & 3,64 & Baik \\
\hline $\begin{array}{l}\text { Bersedia bekerja melebihi } \\
\text { dari yang biasa diharapkan } \\
\text { untuk membantu } \\
\text { organisasionalini berhasil } \\
\text { sukses. }\end{array}$ & 3,45 & 12,07 & 24,14 & 34,48 & 25,86 & 3,67 & Baik \\
\hline $\begin{array}{l}\text { Merasa bagian keluarga } \\
\text { pada organisasionalini }\end{array}$ & 0,00 & 5,17 & 34,48 & 37,93 & 22,41 & 3,78 & Baik \\
\hline $\begin{array}{l}\text { Mempunyai rasa memiliki } \\
\text { yang sangat kuat terhadap } \\
\text { organisasiini, }\end{array}$ & 1,72 & 10,34 & 29,31 & 36,21 & 22,41 & 3,67 & Baik \\
\hline Affective Commitment & & & & & & 3,70 & Baik \\
\hline $\begin{array}{l}\text { Berpindah dari } \\
\text { organisasionalsatu } \\
\text { keorganisasionallain } \\
\text { tampaknya tidak etis }\end{array}$ & 6,90 & 22,41 & 32,76 & 22,41 & 15,52 & 3,17 & $\begin{array}{l}\text { cukup } \\
\text { baik }\end{array}$ \\
\hline $\begin{array}{l}\text { Akan sangat berat untuk } \\
\text { meninggalkan } \\
\text { organisasionalini sekarang, } \\
\text { sekalipun diinginkan }\end{array}$ & 6,90 & 15,52 & 37,93 & 29,31 & 10,34 & 3,21 & $\begin{array}{l}\text { cukup } \\
\text { baik }\end{array}$ \\
\hline $\begin{array}{l}\text { Banyak hal dalam } \\
\text { kehidupan akan terganggu } \\
\text { jika memutuskan untuk } \\
\text { meningalkan } \\
\text { organisasionalini sekarang. }\end{array}$ & 8,62 & 22,41 & 31,03 & 24,14 & 13,79 & 3,12 & $\begin{array}{l}\text { cukup } \\
\text { baik }\end{array}$ \\
\hline $\begin{array}{l}\text { Saat ini tetap bekerja di } \\
\text { organisasionalini } \\
\text { merupakan kebutuhan dan } \\
\text { keinginan }\end{array}$ & 6,90 & 10,34 & 37,93 & 36,21 & 8,62 & 3,29 & $\begin{array}{l}\text { cukup } \\
\text { baik }\end{array}$ \\
\hline $\begin{array}{l}\text { Merasa bahwa sedikit } \\
\text { pilihan bila meninggalkan } \\
\text { organisasionalini }\end{array}$ & 5,17 & 18,97 & 31,03 & 22,41 & 22,41 & 3,38 & $\begin{array}{l}\text { cukup } \\
\text { baik }\end{array}$ \\
\hline Continuance commiment & & & & & & 3,23 & cukup \\
\hline
\end{tabular}


Berdasarkan tabel 4 dapat diketahui bahwa persepsi responden mengenai komitmen organisasional dari responden ketiga indikator masing-masing terbukti baik dengan nilai skor rata-rata variable sebesar 3.47 , hal ini dapat dikatakan dalam pengukuran variabel komitmen organisasional memiliki tingkat responden relatif baik. Komitmen karyawan menunjukan tinggi karena banyak karywan yang sudah bekerja lama di ChildFund Timor Leste. Hal itu terjadi karena lingkungan di tempat kerja santat sangat, hubungan kekeluargaan sangat terlihat, rasa sosialnya tinggi antara satu karyawan dengan yang lain. Hasil penelitian telah menunjukan baik maka harapan tingkat komitmen sangat baik.

Sebelum dilakukan analisis jalur, terlebih dahulu dilakukan analisis faktor konfirmatori untuk mengetahui bahwa indikator-indikator dari tiap variabel merupakan indikator yang valid dan reliabel mengukur variabel. Analisis faktor konfirmatori akan mengelompokkan indicator-indikator ke dalam beberapa faktor. Jika semua indikator merupakan indikator konstruk variabel, maka dengan sendirinya akan mengelompok menjadi satu dengan faktor loading yang tinggi. Dari hasil analisis faktor konfirmatori untuk variabel Keadilan Organisasional (X), Kepuasan kerja (Y1) dan Komitmen Organisasional (Y2). Diketahui bahwa semua indikator dari tiap-tiap variabel mempunyai faktor loading dengan nilai di atas 0,777 . Rangkuman hasil analisis faktor konfirmatori disajikan pada Tabel 5 
Tabel 5.

Analisis Faktor Konfirmatori

\begin{tabular}{|c|c|c|c|c|c|}
\hline \multicolumn{2}{|c|}{ Keadilan Organisasional $(\mathrm{X}$} & \multicolumn{2}{|l|}{ Kepuasan kerja (Y1) } & \multicolumn{2}{|c|}{ Komitmen Organisasional(Y2). } \\
\hline Indikator & $\begin{array}{l}\text { Faktor } \\
\text { Loadin } \\
g\end{array}$ & Indikator & $\begin{array}{l}\text { Faktor } \\
\text { Loadin } \\
g\end{array}$ & Indikator & $\begin{array}{l}\text { Faktor } \\
\text { Loading }\end{array}$ \\
\hline $\begin{array}{l}\text { Keadilan Distributif } \\
\text { (X1) }\end{array}$ & 0,873 & $\begin{array}{l}\text { Kepuasan } \\
\text { (Y1.1) }\end{array}$ & 0,882 & $\begin{array}{l}\text { Affective } \\
\text { Commitment } \\
(Y 2.1)\end{array}$ & 0,922 \\
\hline $\begin{array}{l}\text { Keadilan Prosedural } \\
\text { (X2) }\end{array}$ & 0,899 & $\begin{array}{l}\text { Kepuasan tehadap } \\
\text { Penyelia (Y1.2) }\end{array}$ & 0,815 & $\begin{array}{l}\text { Continuance } \\
\text { commiment } \\
(Y 2.2)\end{array}$ & 0,922 \\
\hline $\begin{array}{l}\text { Keadilan } \\
\text { Interaksional } \\
\text { (X3) }\end{array}$ & 0,789 & $\begin{array}{l}\text { Kepuasan } \\
\text { terhadap. } \\
\text { Pekerjaan (Y1.3) }\end{array}$ & 0,777 & & \\
\hline
\end{tabular}

Sumber: Lampiran 5

Dengan memperhatikan Tabel 5 di atas, dari masing-masing indikator konfirmatif yang mengukur indikator keadilan distributif, keadilan procedural, dan keadilan interaksional nampak bahwa seluruh indikator tiap variabel memiliki loading factor di atas 0,777 sehingga dapat dikatakan bahwa indikator valid mengukur variabel

Dalam penelitian ini digunakan analisis jalur (path analysis) untuk menguji pengaruh keadilan organisasional terhadap kepuasan kerja dan komitmen organisasional. Berdasarkan hasil pengolahan data menggunakan program SPSS dapat diketahui hasil regresi untuk sub-struktur 1 dan sub-struktur 2, seperti disajikan pada Tabel berikut

Tabel 6

Hasil Regresi Struktur 1

\begin{tabular}{|c|c|c|c|c|}
\hline \multirow{2}{*}{ Model } & \multicolumn{2}{|c|}{$\begin{array}{l}\text { Unstandardized } \\
\text { Coefficients }\end{array}$} & $\begin{array}{l}\text { Standardized } \\
\text { Coefficients }\end{array}$ & \multirow{2}{*}{ Sig. } \\
\hline & B & $\begin{array}{l}\text { Std. } \\
\text { Error }\end{array}$ & Beta & \\
\hline
\end{tabular}




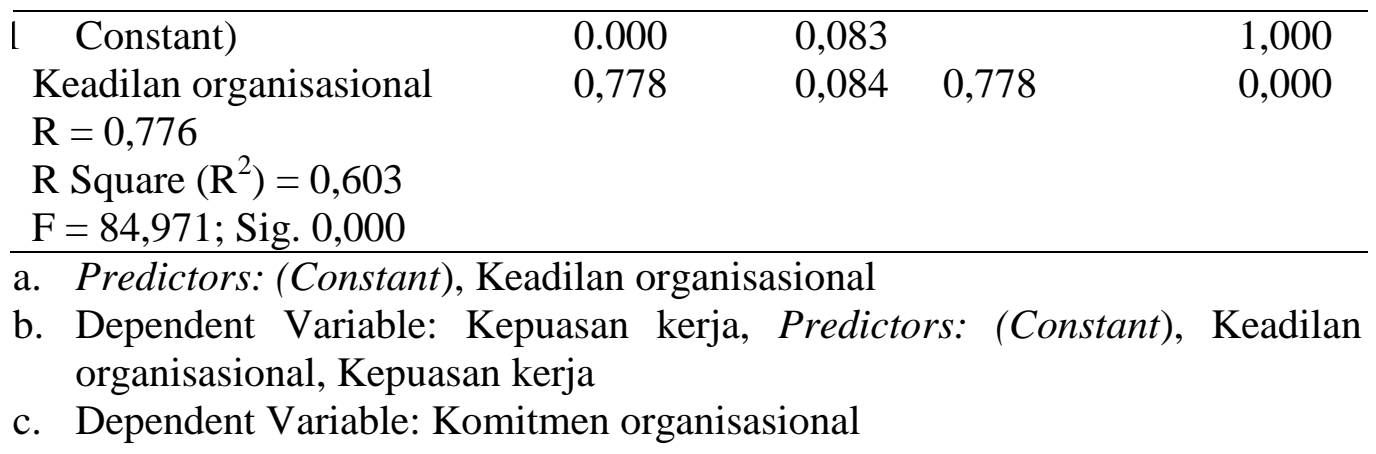

Tabel 7.

Hasil Regresi Struktur 2

\begin{tabular}{|c|c|c|c|c|}
\hline \multirow{2}{*}{ Model } & \multicolumn{2}{|c|}{$\begin{array}{l}\text { Unstandardized } \\
\text { Coefficients }\end{array}$} & \multicolumn{2}{|l|}{ Standardized } \\
\hline & B & $\begin{array}{l}\text { Std. } \\
\text { Error }\end{array}$ & Beta & Sig. \\
\hline Constant) & 0.000 & 0,079 & & 1,000 \\
\hline Keadilan organisasional & 0,586 & 0,126 & 0,586 & 0,000 \\
\hline Kepuasan kerja & 0,263 & 0,126 & 0,293 & 0,042 \\
\hline $\mathrm{R}=0,808$ & & & & \\
\hline R Square $\left(\mathrm{R}^{2}\right)=0,652$ & & & & \\
\hline$F=84,971 ;$ Sig. 0,000 & & & & \\
\hline
\end{tabular}

\section{Hasil Uji Goodness of Fit Model}

Model dikatakan fit jika didukung oleh data empirik. Uji goodness of fit dapat dilihat pada hasil analisis jalur seperti disajikan pada Tabel 5.9 dan Tabel 5.10 di atas. Goodness of Fit model struktural pada analisis jalur berupa nilai Koefisien Determinasi Total $\left(R_{M}^{2}\right)$. Berdasarkan Hasil regresi sub struktur 1 dan sub struktur 2 diketahui nilai $\mathrm{R}^{2}$ masing-masing variabel endogen, yaitu: Kepuasan kerja (Y1) diperoleh $\mathrm{R}^{2}$ sebesar 0,603, dan untuk variabel Komitmen Organisasional (Y2) diperoleh $\mathrm{R}^{2}$ sebesar 0.652. Selanjutnya maka dapat dihitung nilai predictive-relevanc, dengan rumus sebagai berikut.

$$
\begin{aligned}
& R_{M}^{2}=1-\left(1-\mathrm{R}_{1}^{2}\right)\left(1-\mathrm{R}_{2}^{2}\right) \\
& R_{M}^{2}=1-(1-0,603)(1-0,652)=1-(0,397)(0,348)=1-0,138156 \\
& R_{M}^{2}=0,8618
\end{aligned}
$$


Diketahui nilai $R_{M}^{2}=0,8618$ atau 86,18 persen, menunjukkan bahwa keragaman data mampu menjelaskan model 86,14 persen. Hasil ini dapat berarti bahwa Komitmen organisasional dijelaskan oleh Keadilan organisasional dan kepuasan kerja sebesar 86,14 persen dan sisanya 14,86 persen dijelaskan oleh variabel lain yang tidak dianalisis dalam penelitian ini. Dengan demikian model dapat dikatakan baik sehingga layak untuk memberikan penjelasan dan pengujian hipotesis.

Hipotesis diuji dengan t-test pada masing-masing jalur pengaruh langsung secara parsial. Hasil analisis secara ringkas analisis jalur dapat dilihat pada tabel berikut;

Tabel 8.

Hasil Pengujian Hipotesis

\begin{tabular}{|c|c|c|c|}
\hline Hubungan antar Variabel & $\begin{array}{l}\text { Koefisien } \\
\text { Jalur } \\
\text { (Standardize) }\end{array}$ & p-value & Keterangan \\
\hline $\begin{array}{l}\text { Keadilan Organisasional }(\mathrm{X}) \rightarrow \\
\text { Kepuasan kerja }(\mathrm{Y} 1)\end{array}$ & 0,778 & 0,000 & Signifikan \\
\hline $\begin{array}{l}\text { Keadilan Organisasional (X) } \rightarrow \\
\text { Komitmen Organisasional (Y2) }\end{array}$ & 0,586 & 0,000 & Signifikan \\
\hline $\begin{array}{l}\text { Kepuasan kerja (Y1) } \rightarrow \text { Komitmen } \\
\text { organisasional (Y2) }\end{array}$ & 0,293 & 0,042 & Signifikan \\
\hline
\end{tabular}

Hasil pengujian hipotesis jalur-jalur pengaruh langsung juga dapat dilihat pada gambar diagram jalur sebagai berikut 


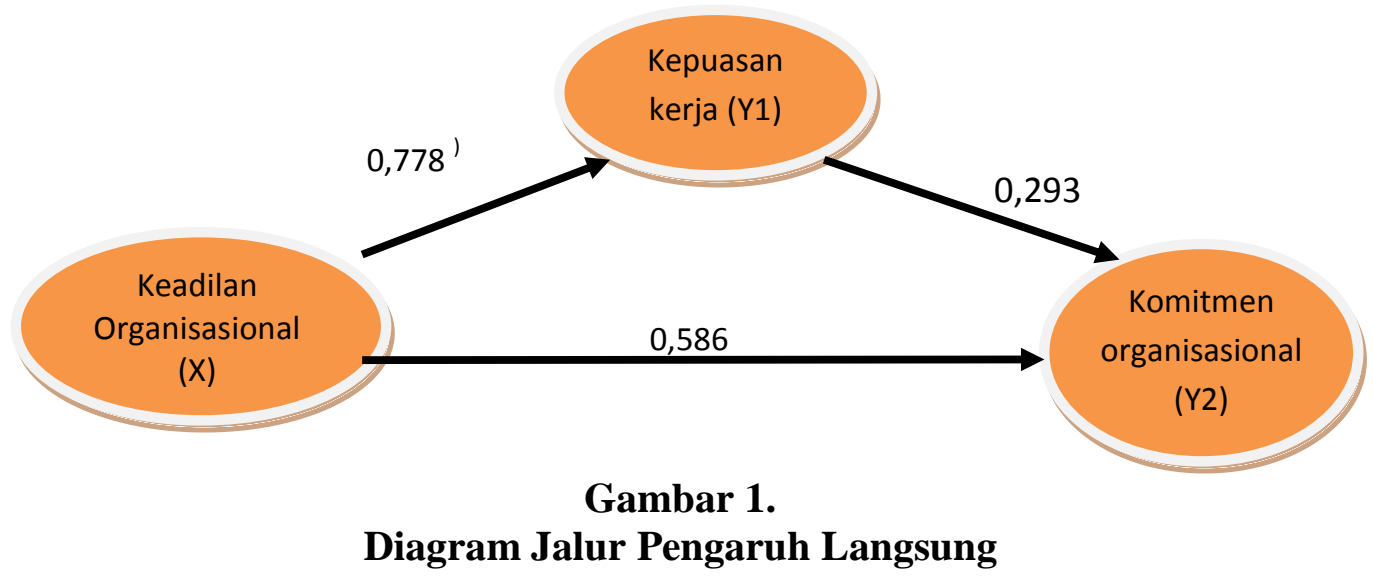

1) Keadilan organisasional $(\mathrm{X})$ berpengaruh signifikan terhadap Kepuasan kerja (Y1). Hasil analisis diperoleh koefisien jalur sebesar 0,778 dengan $\mathrm{P}=0,000$ sehingga dikatakan signifikan. Mengingat koefisien jalur bertanda positif, dapat diartikan bahwa semakin baik Keadilan organisasional (X) maka kepuasan kerja (Y1) juga semakin baik atau semakin puas.

2) Keadilan organisasional $(X)$ berpengaruh signifikan terhadap komitmen organisasional (Y2). Hasil analisis diperoleh koefisien jalur sebesar 0,586 dengan $\mathrm{P}=0,000$ sehingga dikatakan signifikan. Mengingat koefisien jalur bertanda positif, dapat diartikan bahwa semakin baik keadilan organisasional (X) maka komitmen organisasional (Y2) juga semakin baik.

3) Kepuasan kerja (Y1) berpengaruh signifikan terhadap komitmen organisasional (Y2). Hasil analisis diperoleh koefisien jalur sebesar 0,293 dengan $\mathrm{P}=0,042$ sehingga dikatakan signifikan. Mengingat koefisien jalur bertanda positif, dapat diartikan bahwa semakin baik kepuasan kerja (Y1) maka Komitmen Organisasional (Y2) juga semakin baik. 
Berdasarkan hasil uji hipotesis dan terbukti bahwa keadilan kerja berpengaruh positif dan signifikant terhadap kepuasan kerja karyawan yang meningkatkan dan menurunkan ketidak puasan terhadap pekerjaan. Keadilan organisasi dapat dilihat dari kepuasan karyawan terhadap pekerjaan sendiri. Keadilan terhadap imbalan, procedural, keadilan terhadap kesempatan promosi.

Penelitian Babakus et.al (1996) berhasil membuktikan bahwa keadilan kompensasi pada akhirnya akan mengarah pada munculnya kepuasan. Hal ini dimungkinkan, karena keadilan kompensasi akan mengakibatkan timbulnya motivasi dalam diri karyawan. Selanjutnya motivasi ini akan berakibat pada timbulnya kepuasan kerja karyawan. Keadilan kompensasi menjadi salah satu aspek yang patut diperhatikan oleh perusahaan atau organisasi. Jumlah keadilan kompensasi yang diterima pekerja upah merupakan faktor multivariable yang signifikan dan kompleks dalam kepuasan kerja. Upah yang diterima harus dapat memenuhi kebutuhan hidupnya sehari-hari dan tingkat upah yang diterima pekerja mencerminkan sejauh mana pihak manajemen perusahaan menghargai kontribusi pekerjaan seseorang dalam organisasional tempat mereka bekerja.

Berdasarkan hasil uji hipotesis dan terbukti bahwa kepuasan kerja berpengaruh positif dan signifikan terhadap komitmen organisasi. Kepuasan kerja yang menigkatkan dan menurunkan ketidak puasan terhadap karyawan. Kepuasan kerja dapat dilihat dari komitmen karyawan terhadap organisasi atau pekerjaan itu sendiri. Kepuasan karyawan terhadap gaji, kepuasan kerja terhadap kesempatan promosi, kepuasan kerja terhadap suasana rekan kerja, kepuasan kerja terhadap pemimpin dan bawahan. 
Berdasarkan hasil uji hipotesis dan terbukti bahwa keadilan kerja berpengaruh positif dan signifikant terhadap kepuasan kerja karyawan yang meningkatkan dan menurunkan ketidak puasan terhadap pekerjaan. Keadilan organisasi dapat dilihat dari kepuasan karyawan terhadap pekerjaan sendiri. Keadilan terhadap imbalan, procedural, keadilan terhadap kesempatan promosi. Penelitian. Penelitian tentang keadilan organisasional mengalami perkembangan yang sangat pesat pada beberapa tahun terakhir.Secara spesifik, Folger dan Cropanzano Parker dan Kohlmeyer (2005), mendefinisikan keadilan organisasional sebagai kondisi pekerjaan yang mengarahkan individu pada suatu keyakinan bahwa mereka diperlakukan secara adil atau tidak adil oleh organisasinya.

\section{SIMPULAN DAN SARAN}

Berdasarkan hasil analisis dan pembahasan dapat juga disajikan beberapa simpulan berikut: Keadilan organisasional berpengaruhi positif dan signifikan terhadap kepuasan kerja. Hal ini berarti bahwa semakin baik keadilan dalam organisasi maka kepuasan kerja makin meningkat. Kepuasan kerja berpengaruhi positif dan signifikan terhadap komitmen organisasional. Hal ini berarti bahwa makin puas karyawan dalam bekerja maka komitmen organisasional makin tinggi. Komitmen berpengaruhi positif dan signifikan terhadap karyawan. Hal ini berarti bahwa semakin baik komitmen organisasional yang dimiliki oleh karyawan, semakin baik juga kinerja karyawan tersebut. 
Berdasarkan hasil penelitian ini, ada beberapa hal yang dirasakan dalam upaya mencapai keadilan organisasional dan kepuasan kerja terhadap komitmen organisasional pada ChildFund Timor Leste yang selama ini masih belum optimal antara lain: Keadilan organisasional pada ChildFund Timor Leste perlu terus ditingkatkan karena kinerja karyawan berkaitan dengan kinerja organisasi. Memberikan informasi kepada karyawan untuk bebas mengunkapkan pendapatan tentang kegiatan yang ada dalam organisasi. Memberikan imbalan yang sama sesuai tanggung jawab dan pemberian penghargaan yang layak terhadap karyawan karyawan yang berkualitas. Kepuasan kerja karyawan ditunjukan lewat cara mendapat perhatian dari pimpinan atas arahan yang jelas, tentang tingkat kenaikan gaji sesuai sistem yang ada di ChildFund Timor Leste. Komitmen organisasional harus selalu ditingkatkan dan dikembangkan supaya komitment karyawan ditingkatkan lebig baik, Hal ini dapat dilakukan evaluasi kenerja kerja karyawan untuk mengembangkan dan meningkatkan kinerja staff yang di pandang belum baik.

\section{REFERENSI}

Aydogdu, S., \& Asikgil, B. (2011). An Empirical Study of the Relationship among Job Satisfaction, Organizational Commitment and Turnover Intention, International Review of Management and Marketing.1 (3):4353. Available at:https://docs.google.com/viewer?a=v\&q=cache:2P1FCQ6OzhsJ: www.econjournals. com/index.php/irmm/article/download. Retrieved August 4, 2012.

Bodla, M.A., \& Naeem, B. 2008. What satisfies pharmaceutical sales-force in Pakistan? The International Journal of Knowledge, Culture, \& Change Management. 
Bodla, M.A., \& Naeem, B. 2008a. What Satisfies Pharmaceutical Sales force in Pakistan? The International Journal of Knowledge, Culture, \& Change Management, 8.

Bull, IHF. 2005 The Relationship between Job Satisfaction and Organizational Commitment among High School Teachers in disadvantaged Areas in the Western Cape.

Choi, S., 2011. "Organizational Justice and Employee Work Attitudes: The Federal Case." The American Review of Public Administration, 41(2): 185204.

Clay-Warner, J., J. Reynolds, et al. 2005. "Organizational Justice and Job Satisfaction: A Test of Three Competing Models." Social Justice Research Bakhshi, A., K. Kumar, et al. 2009. "Organizational Justice Perceptions as Predictor of Job Satisfaction and Organization Commitment."

Fatt, C.K., S.E.V. Khin, et al. 2010. "The Impact of Organizational Justice on Employee's Job Satisfaction

Gbadamosi, L. and J.C. Nwosu, 2011. Entrepreneurial Intention, Organizational Justice and Job Satisfaction as Determinants of Employees' Organizational Commitment: Evidence from Babcock University Nigeria.

Gbadamosi, L. and J.C. Nwosu, 2011. Entrepreneurial Intention, Organizational Justice and Job Satisfaction as Determinants of Employees' Organizational Commitment: Evidence from Babcock University Nigeria.

Getahun, S., Sim, B., \& Hummer, D. 2007. Job Satisfaction and Organizational Commitment among Probation and Parole Officers: A Case Study. 13(5).http://www.picj.org/docs/issue5. Accessed on 23rd, March, 2009.

Jahromi, S.A.S., M. Salehi, et al. 2009. "Relationship between organizational justice and organizational commitment with job satisfaction among exceptional schools teachers of Bandar Abbas." Journal of Educational

Jahromi, S.A.S., M. Salehi, et al. 2009. Relationship between organizational justice and organizational commitment with job satisfaction among exceptional schools teachers of Bandar Abbas." Journal of Educational Sciences, 2(5): 7-33 [Article in Farsi].

Kumar, K., A. Bakhshi, et al. 2009. "Organizational Justice Perceptions as Predictor of Job Satisfaction and Organizational Commitment." The IUP Journal of Management Research, 8(10): 24-37.

Kumar, K., A. Bakhshi, et al. 2009. Organizational Justice Perceptions as Predictor of Job Satisfaction and Organizational Commitment." The IUP Journal of Management Research, 8(10): 24-37 
Malik, E.M., Nawab, S., Naeem, B., \& Danish, Q.R. (2010). Job Satisfaction and Organizational Commitment of University Teachers in Public Sector of Pakistan. International Journal of Business and Management,

Malik, M. E. and B. Naeem, 2011. "Role of Perceived Organizational Justice in Job Satisfaction: Evidence from Higher Education Institutions of Pakistan." Interdisciplinary Journal of Contemporary Research in Business.

Malik, M.E. and B. Naeem, 2011. "Impact of Perceived Organizational Justice on Organizational Commitment of Faculty: Empirical Evidence from Pakistan." Interdisciplinary Journal of Research in Business.

Malik, M.E. and B. Naeem, 2011. "Impact of Perceived Organizational Justice on Organizational Commitment of Faculty: Empirical Evidence from Pakistan." Interdisciplinary Journal of Research in Business.

Malik. 2010. Motivation factors at university of Baluchistan. Serbian Journal of Management.

Manzoor, M.U., Usman, M., Naseem, M.A., \& Shafiq, M.M. (2011). A Study of Job Stress and Job Satisfaction among Universities Faculty in Lahore, Pakistan Global Journal of Management and Business Research, 11(9):1 September 2011.

Mello, J.A., 2005. Strategic Human Resource Management, Thomson/SouthWestern.

Meyer, J.P. and N.J. Allen, 1997. Commitment in the workplace: Theory, research, and application, Sage publications, inc.

Moynihan, D.P., \& Pandey, S.K. (2007). Finding Workable Levers over Work Motivation Comparing Job Satisfaction, Job Involvement, and Organizational Commitment. University of Wisconsin-Madison, the University of Kansas, Lawrence. Available at: http://aas.sagepub.com Retrieved January 17, 2012.

Najafi, S., A. Noruzy, et al. 2011. "Investigating the relationship between organizational justice,psychological empowerment, job satisfaction, organizational commitment and organizational citizenship behavior: An empirical model." African Journal of Business Management

Najafi, S., A. Noruzy, et al. 2011. "Investigating the relationship between organizational justice, psychological empowerment, job satisfaction, organizational commitment and organizational citizenship behavior: An empirical model." African Journal of Business Management, 5(13): 52415248.

Noordin, F., Jusoff, K. (2009). Levels of Job Satisfaction amongst Malaysian Academic Staff, Asian Social Science, Retrieved February 17, 2012. 
Norris, A.E., 2005. Path Analysis. Statistical Methods for Health Care Research. B. H. Munro, Lippincott Williams \& Wilkins

Park, S., Henkin, A.B., \& Egley, R. 2005. Teacher team commitment, teamwork, and trust: exploring associations, Journal of Educational Administration

Poursoltani, H., F. Mirzaei, et al. 2011. "The relationship between perception of justice and job satisfaction in sport science research center of ministry of science, research and technology's staffs." Management of Sport and Movement Sciences.

Poursoltani, H., F. Mirzaei, et al. 2011. "The relationship between perception of justice and job satisfaction in sport science research center of ministry of science, research and technology's staffs." Management of Sport and Movement Sciences, 1(1): 59-70[Article in Farsi].

Sabri, P.S., Ilyas, M., \& Amjad, Z. 2011. Organizational Culture and Its Impact on the Job Satisfaction of the University Teachers of Lahore. International Journal of Business and Social Science. 2(24) [Special Issue - December 2011] 121.

Safania, A.M., L. Sabaghan-Rad, et al. 2010. "Simple and Multiple Relationships of Organizational Justice and Organizational Commitment of I.R.Iran Sport Organization Employees." Jahesh, 2(5): 51-59[Article in Farsi]. International Journal of Business and Management, 4(9): 145-154.

Seyed Javadin, S.R., M.M. Faraahi, et al. 2009. "How different dimensions of organizational justice affect the different dimensions of job and organizational satisfaction." Journal of Business Management.

Shamsuri, N.A., 2004. Organizational Justice As a Determinant of Job Satisfaction and Organizational Commitment : A Study Among Lecturers and Assistant Registrars in Universiti Utara Malaysia. Master of Science, Universiti Utara Malaysia.

Yaghoubi, M., S. Saghaian Nejad, et al. 2009. "Organizational Justice, Job Satisfaction and Organizational Commitment in the Hospital Staffs; Medical University of Isfahan (MUI)." Journal of Health Administration12(35): 2532 [Article in Farsi].

Yavuz, M., 2010. The effects of teacher' perception of organizational justice and culture on organizational commitment. African Journal of Busines Management.

Zeinabadi, H. and K. Salehi, 2011. "Role of procedural justice, trust, job satisfaction, and organizational commitment in Organizational Citizenship Behavior (OCB) of teachers: Proposing a modified social exchange model." Procedia - Social and Behavioral Sciences. 